\title{
Uma história de dois dinheiros: Salários e gorjetas em dois casinos portugueses
}

A tale of two moneys: tips and wages in two Portuguese casinos

\section{João Gomes}

\section{(2) OpenEdition}

12 Journals

Edição electrónica

URL: http://journals.openedition.org/aa/6681

DOI: $10.4000 / a a .6681$

ISSN: 2357-738X

Editora

Programa de Pós-Graduação em Antropologia Social (UnB)

\section{Edição impressa}

Paginação: 264-286

ISSN: 0102-4302

Refêrencia eletrónica

João Gomes, «Uma história de dois dinheiros: Salários e gorjetas em dois casinos portugueses»,

Anuário Antropológico [Online], v.45 n.3 | 2020, posto online no dia 16 setembro 2020, consultado o 27 abril 2021. URL: http://journals.openedition.org/aa/6681 ; DOI: https://doi.org/10.4000/aa.6681

\section{(c) (i) (9)}

Anuário Antropológico is licensed under a Creative Commons Atribuição-Uso Não-Comercial-Proibição de realização de Obras Derivadas 4.0 International. 


\title{
Uma história de dois dinheiros: Salários e gorjetas em dois casinos portugueses
}

\author{
A tale of two moneys: tips and wages in two Portuguese casinos \\ DOI: https://doi.org/10.4000/aa.6681
}

\begin{abstract}
João Gomes • Universidade de Lisboa - Portugal
Doutorando em Antropologia Social e Cultural no Programa de Doutoramento do Instituto Superior de Ciências Sociais e Políticas, Instituto de Ciências Sociais da Universidade de Lisboa e bolsista de pesquisa da Fundação para a Ciência e Tecnologia (FCT).
\end{abstract}

ORCID: $\odot \odot \odot \odot-\odot \odot \odot 2-3954-1977$ joao.nicolau.gomes@gmail.com

Ao contrário do que sucede na maioria dos contextos laborais, a componente remuneratória mais relevante para os trabalhadores dos dois casinos analisados neste artigo são as gratificações ${ }^{1}$ e não o salário. As gratificações e o salário são duas materializações do mesmo princípio económico: o dinheiro. Ao mesmo tempo, refletem quantidades semeIhantes nos rendimentos globais dos pagadores de banca ${ }^{2}$ de casino. No entanto, assumem qualidades divergentes. Gratificações e salários são representados de formas distintas e, muitas vezes, antagonistas. A "economia moral" que regula os comportamentos e atitudes dos profissionais de banca em relação às gratificações é manifestamente distinta da que está associada aos salários. A centralidade desta componente remuneratória na experiência laboral destes trabalhadores favorece a constituição de "habitus profissionais" discrepantes em relação a outras frações da classe trabalhadora. Este artigo, inserido na subdisciplina da antropologia económica e baseado numa investigação etnográfica, procura analisar os "mapas cognitivos" e os "universos simbólicos" associados às gratificações e aos salários, bem como as suas implicações na experiência profissional destes trabalhadores.
Contrary to what happens in most professional contexts, tips are the most relevant form of remuneration for the casino workers analyzed in this article. Tips and wages are two materializations of the same economic principle: money. At the same time, they reflect similar quantities in the overall remuneration of dealers/croupiers. However, they are qualified in very different ways. Tips and wages are regulated by two distinctive and often antagonistic "moral economies" that produces a very discrepant professional "habitus" in relation to other fractions of the working class. This article, inserted in the subdiscipline of economic anthropology and based on ethnographic research, seeks to analyze the "cognitive maps" and "symbolic universes" associated with tips and wages and the professional experiences that they implicate.

Casinos. Work. Money. Tips. Wages. 


\section{Introdução}

É o melhor dos dinheiros, é o pior dos dinheiros. Esta referência dickensiana ${ }^{3}$ resume o principal argumento deste artigo, a saber: as gratificações e os salários são representados e agenciados de formas bastante diferentes pelos pagadores de banca dos dois casinos portugueses analisados neste artigo ${ }^{4}$. Por sua vez, estas diferentes representações e ações, conjugadas com a centralidade histórica das gratificações nos rendimentos globais destes trabalhadores, favoreceram a constituição de "habitus" (Bourdieu, 2010) profissionais especificamente adaptados ao contexto laboral dos casinos em Portugal. As gratificações produziram dinâmicas laborais particulares e, as mais das vezes, antagonistas em relação ao movimento sindical e operário mais amplo, centrado na luta pelos salários.

Os salários e as gratificações são duas materializações do mesmo princípio económico: o dinheiro. Ao mesmo tempo, possuem, na atualidade, um peso quantitativo semelhante nos rendimentos globais dos pagadores de banca de casino. No entanto, são materialidades regidas por lógicas sociais e culturais distintas, por “economias morais" (Thompson, 2008) divergentes. Enquanto o salário funciona sob preceitos legais e institucionais que o configuram como uma obrigação da entidade patronal, conduzindo a sentimentos de injustiça e de antagonismo, as gratificações são percecionadas em torno de valores e práticas distintas, como o "voluntarismo" e a "generosidade" dos clientes, transportando consigo sentimentos de "felicidade". Da mesma forma, enquanto o salário está intimamente ligado à condição proletária, as gratificações permitem o afastamento material (pelo seu valor objetivo) e simbólico (pela ideologia que transportam) destes profissionais em relação a outras frações da classe trabalhadora. Posteriormente, estas diferenças repercutem-se na importância atribuída pelos trabalhadores a cada uma destas componentes remuneratórias. Enquanto o salário só recentemente passou a ser alvo de manifestações de interesse laboral, as gratificações possuem um longo historial de mobilização e dinamização da atividade sindical. Desta forma, as gratificações, ao contrário do salário, monopolizaram e monopolizam os interesses de classe destes profissionais. As gratificações, porque implicam, não apenas diferentes "mapas cognitivos" e "universos simbólicos" (Santos, 1985, p. 882) mas, igualmente, diferentes estratégias de luta e apropriação, produzem "habitus" e experiências profissionais e de classe antagonistas em relação a outras frações da classe trabalhadora, mais dependentes da retribuição salarial. O corporativismo, as políticas de closed shop, o clientelismo e outros mecanismos de "oclusão social" (Weber, 1968; Parkin, 1979) hegemonizaram sempre as estratégias do movimento sindical nos casinos. Para proteger o valor das suas gratificações, tanto menor quanto a mais pessoas distribuir, os pagadores de banca procuraram sempre, ao longo da sua história, "erigir barreiras contra os trabalhadores de fora", visando "a manutenção do segredo da arte" (Mónica, 1986, p. 53, 91). Este "entrincheiramento" na sua própria profissão, apesar de tudo, não representa uma "opção", mas um “constrangimento" (Patriarca, 1994, p. 813), dado que as gratificações garantem a estes trabalhadores a reprodução de um nível de vida e de padrões de consumo superiores à condição estruturalmente subordinada que lhes está reservada no
1 Gratificação é a designação formal das gorjetas nos casinos em Portugal.

2 Pagador de banca é a designação oficial portuguesa da categoria profissional dos dealers/croupiers.

3 Charles Dickens, no seu livro História de duas cidades, reportando-se às cidades de Londres e de Paris na época da Revolução Francesa, assinalava: "era o melhor de todos os tempos, era o pior de todos os tempos".

4 Os casinos e os interlocutores mencionados neste artigo estão protegidos pelo anonimato. Todos os nomes presentes neste texto são fictícios. 
trabalho e na sociedade pela mera retribuição salarial.

As coisas têm uma "vida social" (Appadurai, 2000), transportam consigo materialidades e ideologias que exercem constrangimentos sobre a agência humana. Nesta relação dialética, elas coproduzem a realidade, os habitus e as representações. Elementos de "distinção" (Bourdieu, 2010), as gratificações são o veículo material e simbólico que comanda a experiência laboral e relacional dos trabalhadores dos dois casinos analisados.

Este artigo tem por base uma investigação etnográfica iniciada em Junho de 2017 sobre "o trabalho nos casinos em Portugal", um terreno de investigação ainda largamente por explorar dada a selectividade, exclusivismo e secretismo associados às profissões no setor do jogo. Durante 4 meses, entre Junho e Setembro de 2017, realizei observação participante, exercendo a função de contínuo ${ }^{5}$ num casino em Portugal. Posteriormente, entre Fevereiro e Outubro de 2018, realizei 46 entrevistas semi-estruturadas a 40 profissionais de dois casinos (24 pagadores de banca) pertencentes à mesma concessionária, momento que dependeu da aplicação da técnica da "bola de neve". De seguida, entre Outubro de 2018 e Fevereiro de 2019, frequentei o curso de pagador de banca de casino, um segundo momento de observação participante que me permitiu experienciar as formas de integração na categoria de pagador de banca e a aprendizagem das competências profissionais necessárias ao seu exercício ${ }^{6}$. Por fim, entre março e outubro de 2019, efetuei uma intensa pesquisa documental e arquivística sobre a história do movimento sindical nos casinos.

\section{Uma breve história dos salários e das gratificações nos casinos em Portugal}

A primeira regulamentação do jogo em Portugal data de 3 de dezembro de 1927, com a publicação do Decreto-Lei n ${ }^{\circ} 14643$ (Diário do Governo no 267/1927, série I). Antes desta data, os casinos em Portugal operavam na clandestinidade, assumindo o nome de "clubs" ou "casas de recreio" (Vaquinhas, 2006). As condições de trabalho dos pagadores de banca de casino eram caraterizadas pela informalidade, insegurança, precariedade e sazonalidade laboral (Associação de Classe dos Empregados dos Clubs e Casas de Recreio de Lisboa, 1929). Empurrados para a ilegalidade, os trabalhadores da indústria do jogo subsistiam graças à prática informal, mas quase institucionalizada, das gorjetas. No entanto, a dependência em relação às gorjetas não era uma caraterística exclusiva dos profissionais do setor do jogo. Segundo Américo Nunes (2007), os trabalhadores do setor da hotelaria, classificados como "criados domésticos" e não como "trabalhadores assalariados", não só obtinham a totalidade dos seus rendimentos através das gorjetas concedidas pelos clientes, como eram ainda obrigados a ceder parte destes ganhos aos respetivos patrões. Apesar desta condição partilhada, os trabalhadores da hotelaria e do jogo diferenciavam-se pela forma como representavam e agenciavam as suas gratificações. Para os primeiros, a ausência de retribuição salarial legitimava a sua classificação como "criados domésticos" pelo Estado e pelo patronato (Ibid.). Justificava, igualmente, a sua não inclusão nos diplomas legais que melhoravam significativamente as condições de trabalho dos "traba-
5 Os contínuos são uma categoria profissional não especializada, cujas funções são muito variadas: arrumação e limpeza da sala de jogo, abertura de bancas, reposição do stock de fichas das bancas, atendimento personalizado aos jogadores, entre outras.

6 O ingresso no terreno foi autorizado pela entidade empregadora. Esta informação, por sua vez, foi transmitida de forma faseada aos meus colegas de trabalho, isto é, à medida que ganhava alguma familiaridade com eles.

7 Classificação que se manteve até a publicação do Decreto-Lei n ${ }^{\circ}$ 24402, de 24 de agosto de 1934 (Diário do Govêrno n. ${ }^{\circ}$ 199/1934, série I). 
lhadores assalariados" (Ibid.), como a aplicação do horário de trabalho das 8 horas diárias (48 horas semanais) estabelecido pelo Decreto-Lei $n^{\circ} 5516$ de 7 de maio de 1919 (Diário do Govêrno n. 9 95/1919, série I). Como tal, os trabalhadores do setor hoteleiro reivindicavam a sua pertença ao operariado e, a partir da década de 1920, iniciavam uma campanha pela "abolição da gorjeta" (Nunes, 2007, p. 174). Esta era considerada uma "esmola vexante" (Ibid., p. 188), instrumento da sua opressão. Em sua substituição, os sindicatos do setor propunham a implementação de uma "taxa de serviço" (normalmente, de 10\%) a cobrar diretamente na conta do cliente (Ibid.). Esta proposta do movimento sindical hoteleiro nunca encontrou eco junto dos profissionais do setor do jogo, dado que a gorjeta nos casinos nunca foi concebida como uma "esmola vexante" ou como uma humilhação a que os profissionais deveriam sujeitar-se ${ }^{8}$. Se, para os trabalhadores do setor hoteleiro, as gratificações representavam a exclusão e a opressão, para os profissionais da indústria do jogo, ao invés, representavam o instrumento da sua "distinção" e o garante do seu privilégio profissional. Se os primeiros reivindicavam a sua pertença ao operariado, os segundos reclamavam a sua diferenciação. Para os primeiros, as gratificações impediam a sua inclusão na classe operária, para os segundos, elas legitimavam o seu entrincheiramento profissional, isto é, a sua distância e o seu privilégio em relação a ela.

A Associação de Classe dos Empregados dos Clubs e Casas de Recreio de Lisboa (ACECCRL), fundada em 1925, era um organismo corporativo antes da institucionalização do regime corporativo. Como veremos mais abaixo, a ACECCRL reivindicava, logo em 1929, o controlo do mercado de trabalho, defendendo a mediação da associação nos processos de recrutamento das empresas concessionárias (Associação de Classe dos Empregados dos Clubs e Casas de Recreio de Lisboa, 1929). Posteriormente, o Sindicato Nacional dos Empregados de Banca nos Casinos (SNEBC), fundado em 1934, iria usar e abusar dos instrumentos legais disponibilizados pelo corporativismo do Estado Novo, como a sindicalização obrigatória e a concessão/renovação da carteira profissional (Patriarca, 1994), implementando, inclusivamente, práticas de closed shop sancionadas pelo regime. Em 1952, era o próprio Instituto Nacional do Trabalho e Previdência (INTP) que assinalava:

Parece-nos lógico e natural que os empregados de banca, e só estes, não devem ser livremente recrutados em meio estranho à actividade, e supomos até que as próprias empresas nisso estarão interessadas, pela sua especialidade, pelos aspectos morais que reveste e pelas dificuldades que the são inerentes, só lhes interessam homens com experiência e conhecimentos adquiridos ao longo de vários anos de exercício profissional (Acordo Colectivo de Trabalho entre várias empresas concessionárias de jogo e o Sindicato Nacional dos Empregados de Banca nos Casinos. Ofício 54. AN/ TT, SAS/003/002/00088, s/p).

Atualmente, o declínio do movimento sindical corporativo no setor do jogo é compensado pela perpetuação de relações clientelistas que reproduzem a res-
8 Para o setor hoteleiro, as gratificações foram mesmo abolidas em 1932, com a publicação do Decreto-Lei n ${ }^{\circ} 1861$, de 15 de novembro (Diário do Governo n²68/1932, série I). 
trição no acesso à categoria profissional de pagador de banca. Durante todo o meu trabalho de campo, foram raros os trabalhadores que confessaram não possuir uma "cunha" no casino. Em toda a história da profissão, acompanhando esta tendência de "oclusão social" e profissional, os salários foram sistematicamente negligenciados em detrimento das gratificações. Aliás, apenas encontramos reivindicações salariais no Relatório de Direcção e Parecer da Comissão Revisora de Contas relativo a 1929 (Associação de Classe dos Empregados dos Clubs e Casas de Recreio de Lisboa, 1929). Porém, mesmo neste caso, as gratificações já impunham a sua centralidade junto desta classe profissional. Segundo o documento (Ibid., p. 11), as principais reivindicações da ACECCRL consistiam: 1) no estabelecimento de contratos de trabalho, com a duração mínima de 3 meses, entre os sócios da ACECCRL e as empresas, mas por intermédio da associação; 2) na fixação de ordenados mínimos para empregados de banca permanentes e temporários de 60 \$ diários acrescidos de 15 \$ de ajudas de custos; 3) na determinação de horários de trabalho de 8 horas diárias; 4) na divisão do trabalho por dois turnos compostos por igual número de empregados; 5) e na repartição integral do produto da caixa de gratificações "pelos empregados, como se praticava anteriormente à regulamentação, visto ser essa, sem dúvida, a intenção dos parceiros ${ }^{9}$ que as concedem”. Manifestamente, a maior preocupação dos trabalhadores prendia-se com a "participação dos industriais nas gratificações", o que representava "uma prática indigna” (Ibid., p. 9-10).

Os primeiros Acordos Coletivos de Trabalho (ACT) da indústria do jogo, celebrados na década de 1940, apontavam no mesmo sentido. Tomando como exemplo o ACT assinado em 1945 entre o SNEBC e a Estoril-Plage, empresa concessionária da zona de jogo do Estoril (Boletim do Instituto Nacional do Trabalho e Previdência, 1945, ano XII), o documento estipulava, pela primeira vez, os ordenados dos "empregados de banca" (1650\$), “fiscais de banca"10 (2000\$), “ficheiros-fixos"11 (1200\$) e "ficheiros-volantes"12 (1000\$) (Ibid., cláusula 29). Mas garantia aos trabalhadores, igualmente, a retenção integral das suas gratificações: "os empregados de banca e os fiscais de banca vencerão integralmente as gratificações que lhes são oferecidas pelos frequentadores do casino" (Ibid., cláusula $30^{\circ}$, p. 12).

A revisão destes ACT's na década de 1970 acentuava, significativamente, a centralidade das gratificações em relação aos salários. Destes novos acordos desapareciam as cláusulas relativas aos "ordenados”, surgindo, em sua substituição, a fórmula das "retribuições" ou "vencimentos mínimos”. Tal não constituía uma novidade. Outros setores de atividade e categorias profissionais consagravam este conceito nos seus respetivos ACT's. No entanto, para a maioria da classe trabalhadora nacional, as "retribuições mínimas" representavam apenas uma outra designação para os salários. Inversamente, nos casinos portugueses, dada a existência das gratificações, as "retribuições mínimas" poderiam assumir um novo significado, isto é, em detrimento de um salário garantido, pago obrigatoriamente pelas empresas concessionárias, os rendimentos destes trabalhadores poderiam agora derivar exclusivamente das gratificações. Tal não constituía uma obrigatoriedade e, em alguns casinos, as "retribuições mínimas" correspondiam, efetivamente,
9 Parceiros é a designação que ainda hoje é utilizada pelos trabalhadores dos casinos portugueses para se referirem aos clientes.

10 Esta função operacional consiste na fiscalização da legalidade do jogo, das atividades dos pagadores de banca e dos jogadores.

11 Atualmente, esta função designa-se por caixa e tem como principais responsabilidades a conversão do dinheiro em fichas, quando os clientes pretendem jogar, e a conversão das fichas em dinheiro, quando os jogadores pretendem abandonar o casino.

12 Esta categoria profissional, entretanto, extinta, consistia na venda ambulante de fichas nas salas de jogos. 
aos ordenados pagos pelas empresas, aos quais acresciam ainda as gratificações. Mas noutros, as gratificações passaram a ser enquadradas na fórmula das "retribuições mínimas". Neste sentido, as "retribuições mínimas" dispensavam alguns casinos de remunerar os seus próprios empregados sempre que as gratificações atingissem o valor estipulado pelos ACT's. O Decreto-Lei n $n^{\circ} 43044$ de 2 de julho de 1960 (Diário do Governo $n^{\circ} 152 / 1960$, série I, artigo 13º, p. 1632) já previa que as gratificações pudessem "ser consideradas como ordenado ou salário, no todo ou em parte, para efeito de previdência e abono de família, respondendo neste caso tais gratificações pela percentagem de 50 por cento dos respectivos encargos patronais". Várias empresas aproveitaram estas disposições para incluir as gorjetas nas "retribuições mínimas". Foram os casos dos ACT's relativos aos casinos do Algarve (Boletim do Trabalho e Emprego, 1977, $1^{\text {a }}$ série, número 21, volume 44) e da Figueira da Foz (Id., 1979, $1^{\text {a }}$ série, número 9, volume 46). O primeiro assinalava: "a) as quantias [das retribuições mínimas] devem ser pagas quando as gratificações a que os trabalhadores têm direito não existam" e "b) parcialmente quando as mesmas gratificações não atinjam o valor da garantia” (Id., 1977, $1^{\text {a }}$ série, número 21, volume 44, cláusula $25^{\mathrm{a}}$, número 7). Da mesma forma, o segundo mencionava:

Consideram-se incluídas nas retribuições mínimas mensais as garantias de vencimento dadas pela entidade patronal aos trabalhadores mesmo quando não haja o seu efectivo pagamento, total ou parcialmente, em virtude da existência de gorjetas/gratificações a que os trabalhadores têm direito (Id., 1979, $2^{\text {a }}$ série, volume 46, cláusula 23a , número 2, p. 83).

Mas não era apenas na celebração dos ACT's que se observava a primazia das gratificações sobre os salários. A ausência de reivindicações salariais contrastava sempre com a acutilante dinamização sindical mobilizada pela temática das gratificações. Em particular, o movimento sindical nos casinos centrava as suas preocupações na formalização de regras e procedimentos para a distribuição das gratificações entre as várias categorias profissionais (Gomes, 2019). Mais do que uma luta comum por aumentos salariais, a determinação de regras oficiais para uma distribuição assimétrica das gratificações monopolizava os interesses de classe destes trabalhadores. Mais do que uma luta contra o privilégio, esta era uma luta pelo privilégio, isto é, pela apropriação de uma maior parte das gorjetas (Ibid.). Os pagadores de banca, que se encontravam hegemonicamente representados no sindicato corporativo, conseguiram, sistematicamente, garantir o privilégio de receber uma maior porção deste valor. Logo em 1945, o ACT assinado entre o SNEBC e a Estoril-Plage determinava que os pagadores de banca receberiam 3/4 das gratificações e os fiscais de banca apenas 1/4 (Boletim do Instituto Nacional do Trabalho e Previdência, 1945, ano XII, cláusula 30ª). Ainda hoje, a distribuição das gratificações nos casinos privilegia a categoria profissional dos pagadores de banca, mas as regras, os procedimentos e as proporções a alocar a cada função operacional foram sendo alteradas de forma frequente (Gomes, 2019).

Um outro exemplo desta dinâmica associativa, centrada nas gratificações e 
não nos salários, ocorre em 1960. Até este ano, os trabalhadores reformados do setor do jogo encontravam-se numa situação bastante vulnerável. Como as gratificações não estavam sujeitas a tributação fiscal, os trabalhadores, descontando apenas sobre os seus baixos salários (quando existiam), encontravam, na reforma, vencimentos muito inferiores aos que estavam acostumados. Os pagadores de banca, procurando evitar uma redução significativa da sua retribuição mensal e do seu nível de vida, permaneciam no seu posto de trabalho até se encontrarem em situação de quase completa incapacidade física ou mental. Por esse motivo, em 1960, o SNEBC cria um fundo, financiado pela tributação das gratificações dos trabalhadores, com o objectivo de complementar a reforma dos seus associados (Despacho Normativo, Boletim do Instituto Nacional do Trabalho e Previdência, 1960, ano XXVII).

A desproporcionalidade entre os salários (quando existiam) e as gratificações era, de facto, bastante significativa. Segundo alguns trabalhadores entrevistados, no início da década de 1970, os salários rondavam os $2000 \$$ mensais $^{13}$, enquanto as gratificações alcançavam valores na ordem dos $15000 \$-20000 \$$ por mês ${ }^{14}$. Numa "nota justificativa" relativa às regras de distribuição das gratificações, redigida pelo Gabinete do Secretário de Estado do Ministério do Trabalho e datada de 21 de janeiro de 1982, disponibilizavam-se os valores das gratificações auferidas pelos trabalhadores do setor do jogo entre os anos de 1974 e 1980 a nível nacional (Gratificações das salas de jogos dos casinos - projectos A e B. Arquivo do Ministério do Trabalho, da Solidariedade e Segurança Social, 1981-1983, TR/2, número 3134). Segundo as informações disponibilizadas, em 1974, os trabalhadores dos casinos do Funchal, de Espinho e da Póvoa do Varzim arrecadaram, respetivamente, 3133 735\$, 12000 000\$ e 13000 000\$ em gorjetas (Ibid.). No Casino do Estoril, entre 1975 e 1980, os profissionais do setor do jogo auferiram 44178 720\$, 50570 530\$, 71488 930\$, 103870 350\$, 145212 640\$ e 180218 640\$, respetivamente (Ibid.). Tal significa que, num espaço de 6 anos, os trabalhadores do Casino do Estoril totalizaram 804575300 \$ em gratificações (Ibid.). No mesmo documento, o Gabinete do Secretário de Estado do Ministério do Trabalho providenciava, inclusivamente, uma comparação entre as gratificações auferidas pelos trabalhadores e o imposto de jogo cobrado pelo Estado às empresas concessionárias (Ibid.). De 1977 a 1981, o imposto de jogo cobrado pelo Estado atingiu o valor total de 2010685472 (Ibid.). Por sua vez, no mesmo espaço temporal, as gratificações, a nível nacional, alcançaram o valor de 2006878 630\$ (Ibid.). Em 1977 e 1978, as gratificações chegaram mesmo a ultrapassar o imposto de jogo cobrado pelo Estado às empresas concessionárias (Ibid.). Como alguns interlocutores referiram em contexto de entrevista, "era um deslumbramento", "uma loucura”, "eram rodos de dinheiro", "ninguém ganhava mais no país".

Observada a desproporção de valores entre os salários e as gratificações, não é de surpreender que estas equipas de trabalho nunca tenham atribuído ao salário a importância, a centralidade e o estatuto de que o mesmo gozou junto de outras classes profissionais. As gratificações, conjugadas com as práticas de "oclusão social" implementadas por estes trabalhadores, garantiam a sua "distinção" só-
13 Segundo a ferramenta informática disponibilizada pelo site PORDATA, 2000\$, em 1970, correspondem, atualmente, a $588,92 €$. De referir que, em 2018 , o salário mínimo em Portugal ascendia a $580 €$ por mês. Por sua vez, o salário médio nacional correspondia a $970 €$ mensais.

14 Segundo o mesmo site, $15000 \$$ equivalem, atualmente, a $4416,88 €$. 
cio-profissional, isto é, a constituição de uma distância material e simbólica em relação a outros grupos da classe trabalhadora. Observamos, por isso, como o principal motor de mobilização e protesto, o principal vetor que orientou a contestação destes profissionais não foi o salário, nem as condições de trabalho em geral, mas as gratificações. Inicialmente, a preocupação prendia-se com a "participação" do patronato nas gratificações. Posteriormente, com as proporções a alocar a cada categoria profissional. De seguida, com a impossibilidade de refletir o valor das gratificações nas reformas dos trabalhadores. Por fim, já na década de 1990, o movimento sindical nos casinos contestou fortemente a tributação das gratificações por parte do Estado ${ }^{15}$. Como podemos constatar, os salários foram sempre negligenciados na história desta categoria profissional. Igor, fiscal de banca com mais de 30 anos de experiência profissional, afirma categoricamente: "antigamente, ninguém queria saber dos salários”. Mesmo hoje, alguns profissionais admitem que só ponderam assumir uma posição mais participativa em termos sindicais se a empresa lhes "mexer nas gratificações". Como tal, são elas que determinam, em grande medida, o movimento sindical nos casinos. As lutas tradicionais dos sindicatos e do movimento operário português, especificamente, a questão salarial, sempre foi um mero apêndice para estes trabalhadores. Por estes motivos, a gratificação não deve ser considerada como mero "dinheiro extra”, em contraposição ao "dinheiro sério" representado pelo salário (Zelizer, 1989). Pelo contrário, as gratificações, historicamente, transformaram o salário numa mera componente periférica, destinada a garantir um rendimento mínimo, numa totalidade composta, principal e fundamentalmente, pelas gratificações.

Naturalmente, esta desconsideração relativa à retribuição salarial, favorecia, em última instância, o capital. Em primeiro lugar, permitia-lhe, pelo achatamento (ou inexistência) dos salários, a sobre-exploração da força de trabalho e a consequente apropriação de uma maior porção da mais-valia produzida. Por outro lado, garantia a "produção de consentimento" (Burawoy, 1979) junto destes trabalhadores, dado que as gratificações, como assinala Rachel Sherman (2007, p. 151), tendem a substituir "as potenciais tensões hierárquicas" pelo "conflito lateral" isto é, a luta potencialmente unitária pelos salários transforma-se num conflito entre as diferentes categorias profissionais pela apropriação de uma maior parte das gorjetas. Mas o capital nunca se encontra sozinho. O Estado foi, igualmente, fundamental neste processo: ao mesmo tempo que abolia as gorjetas no setor hoteleiro, o Estado protegia, através de vários diplomas legais, as gratificações do setor do jogo. Mais, o Estado privilegiava, pela formalização jurídica das proporções a alocar a cada categoria profissional, os pagadores de banca.

Mas como explicar as diferentes posições e estratégias adotadas em relação às gorjetas pelos trabalhadores do setor hoteleiro, por um lado, e pelos profissionais da indústria do jogo, por outro? Talvez este seja um dos casos em que meras diferenças quantitativas (valor das gratificações) se convertem em diferenças qualitativas (diferentes representações e ações) (Marx, 1990). No entanto, como veremos na próxima secção, tal explicação não parece esgotar todo o fenómeno abordado. Isto é, não será por uma mera diferença de valores que as gratificações
15 Os trabalhadores dos casinos afirmam que esta tributação é inconstitucional, dado que são os únicos profissionais que descontam sobre as suas gratificações.

16 "Lateral conflict replaces potential hierarchical tensions". 
nos casinos são representadas e agenciadas de formas distintas. As gratificações nos casinos são regidas por uma "economia moral" particular, carregam "universos simbólicos" e "mapas cognitivos" específicos e produzem, na mesma medida, "habitus" profissionais divergentes. Este será o tema das próximas secções.

\section{Salários vs gratificações}

\section{1 de julho de 2017, sábado, 16:30.}

"O quê? Deste três vezes seguidas o 17? Então espera aí". O jogador debruça-se sobre o pano da roleta e preenche todas as apostas possíveis no número 17. O pleno, os quatro cavalos, os quatro quadros, as duas linhas e a rua ${ }^{17}$. A banca está animada. Apesar do relógio anunciar 16:30, cedo demais para as habituais enchentes do casino, os jogadores estão entusiasmados com o número 17, dado que foi o número vencedor nos últimos três golpes consecutivos. $O$ pagador parece estar deliberadamente a desafiar todas as regras das probabilidades e os jogadores amontoam-se à volta da banca, carregando o pano com fichas no número 17. O pagador lança a bola e o seu rumor a deslizar na roleta preenche a sala. Os jogadores silenciam-se por instantes. Quando a bola perde velocidade, o pagador anuncia: “jogo feito, nada mais!”. Os jogadores estacam e focam-se na bola, os seus olhos acompanham o seu movimento com minúcia. A bola cai no número 17, pela quarta vez consecutiva. Momentaneamente, pagador, fiscal e jogadores sustêm a respiração, revelando um semblante grave. Estão todos estupefactos. Posteriormente, riem-se e trocam galhardetes animados. O pagador afirma: "estão a ver? Só não ganha quem não quer". Os jogadores regozijam e gracejam em conjunto: "agora paga!". A banca tem a atenção da sala inteira. O pagador entrega os respetivos prémios com uma rapidez e destreza assinaláveis. De seguida, todos os jogadores sem exceção, retiram duas ou mais fichas dos seus montes e lançam-nas para o pano. O pagador sorri, eleva a voz e afirma: "gratificação, obrigado!". O fiscal, a observar da sua cadeira, acena e repete: "gratificação, obrigado!".

\section{1 de dezembro de 2018, terça-feira, 18:00.}

"Venham cá todos cinco minutos, se faz favor!" - Ordena um dos formadores do curso de pagador de banca de casino. Na sala de formação instala-se o silêncio, onde antes o rumor das fichas e das bolas a rolar envolvia o espaço. Os novos recrutas aproximam-se com relutância, receosos de serem chamados novamente à atenção. "Oiçam com atenção, quando um cliente vos dá dinheiro para trocar por fichas, vocês expõem o troco no pano e, de seguida, colocam o dinheiro na caixa à vossa direita. À direita do pagador. Têm uma ranhura no pano e colocam lá o dinheiro". Faz uma pausa enquanto procura perceber na cara dos formandos se a informação foi bem recebida e processada. De seguida, continua:

Quando um cliente vos gratifica, sempre em fichas e nunca em dinheiro, vocês colocam as fichas na ranhura que se encontra à vossa esquerda. Se tiverem alguma dificuldade em recordar este procedimento pensem: a gratificação é à esquerda porque é do lado do coração.
17 O pleno é a aposta num único número da roleta. Se a aposta for vencedora, o jogador recebe $35 x$ o valor apostado. Por sua vez, o cavalo é a aposta em dois números e paga $17 x$ o valor da aposta. Os quadros (aposta em quatro números), as linhas (aposta em 6 números) e a rua (aposta em três números) pagam, respetivamente, $8 x, 5 x$ e $11 \mathrm{x}$ o valor das fichas apostadas. 
Boaventura de Sousa Santos (1985) define Portugal como uma sociedade "semiperiférica", marcada "[...] por uma descoincidência articulada entre as relações de produção capitalista e as relações de reprodução social” (Ibid., p. 872). Ou seja, segundo o autor, existe um "atraso [...] das relações entre o capital e o trabalho na esfera da produção, em confronto com as relações de reprodução social, ou seja, as relações sociais que presidem aos modelos e às práticas dominantes do consumo" (Ibid.). A classe trabalhadora, nas sociedades semiperiféricas, depende, em grande medida, de diversos "mecanismos informais compensatórios", que complementem os baixos salários da produção capitalista (Ibid.). A descoincidência entre as relações sociais de produção capitalista e as relações sociais de reprodução nos casinos é representada pela figura das gratificações. Enquanto "mecanismo informal compensatório", as gratificações complementam os baixos salários e elevam o nível de reprodução social, favorecendo o apaziguamento dos conflitos laborais (nomeadamente, descentralizando a importância da luta pelo salário). Em primeiro lugar, as gratificações permitem um relativo desenvolvimento dos padrões e modelos de consumo, isto é, um relativo avanço da reprodução social em relação à produção capitalista, baseada no "achatamento do salário" (Ibid.). Em segundo lugar, este "mecanismo informal compensatório" é portador de "mapas cognitivos", "universos simbólicos" e "habitus de classe" distintos daqueles que caraterizam o antagonismo típico da negociação e luta pela retribuição salarial. Como assinala Rachel Sherman (2007, p. 151), na sua investigação sobre o trabalho em hotéis de luxo, o dinheiro, na forma das gorjetas, "assume novos significados"18. Quais os significados, mapas cognitivos e universos simbólicos implicados na prática da gratificação nestes dois casinos?

No decorrer do meu trabalho de campo observei, com frequência, a dualidade de representações associadas ao salário e às gratificações. Os salários e as gratificações funcionam, de facto, segundo uma "economia moral" diferenciada. Embora as gratificações já tenham representado, no passado, um valor absolutamente desproporcional em relação à retribuição salarial, atualmente, os valores são muito mais equilibrados. Segundo o Acordo de Empresa (AE) em vigor, negociado para os dois casinos analisados, os salários dos pagadores de banca fixam-se nos $917 €$ mensais $^{19}$. As gratificações, por outro lado, são uma componente remuneratória variável mas, normalmente, rondam os 900-1200€ por mês. Ou seja, as gratificações correspondem hoje a 50\%-60\% do rendimento total dos pagadores de banca ${ }^{20}$. No entanto, as representações associadas ao salário e às gratificações continuam a divergir de forma significativa. Segundo os entrevistados, os seus salários são "curtos", "ridículos", "baixos" e "injustos”. Ivo, pagador de banca com cerca de 14 anos de experiência profissional, assinala: "o salário não chega para arrendar uma casa, muito menos para pagar as contas todas”. Helena, pagadora de banca há cerca de 12 anos, aponta no mesmo sentido:

O nosso salário é um abuso, o nosso salário é gritante, o nosso salário é das coisas mais tristes que estão ali. Nós trabalhamos à noite, levamos constantemente com o fumo, temos horários rotativos, dão-nos dinheiro e
18 "[...] money takes on new meanings".

19 De referir que os valores dos salários e das gratificações aqui mencionados dizem respeito apenas aos dois casinos analisados. Os salários divergem consoante os AE's em vigor (quando existem) e o volume de jogo dos casinos. Na grande maioria dos casinos portugueses, os salários rondam os $600 €-700 €$ mensais e as gratificações raramente atingem os $600 €$ por mês.

20 Em Las Vegas, segundo Sallaz (2009), 80\% dos rendimentos dos dealers derivam desta componente remuneratória. 
nós somos responsáveis por aquele dinheiro nas bancas. Temos que estar constantemente a fazer contas, levamos com o barulho, com a música alta, com a falta de educação, com agressões verbais, com carpetes com pulgas, com ar condicionado que não é limpo, passamos frio, outras vezes imenso calor e depois somos mal pagos ${ }^{21}$.

Sobre o salário são projetadas conceções de justiça e injustiça, intimamente relacionadas com as assimetrias de classe presentes na empresa e na sociedade. Ele é sempre associado ao "custo de vida" e "à renda", ele não chega "até ao fim do mês" e "em comparação com outras profissões é injusto". No mesmo sentido, os pagadores de banca entrevistados costumam formular a dicotomia entre o salário e as gratificações da seguinte forma: "o salário é baixo, se não fossem as gratificações...”, e nunca a proposição inversa, igualmente, legítima: "as gratificações são incertas, se não fosse o salário...”. O salário funciona, por isso, sob vetores morais específicos, normalmente, tendo como referência as condições de trabalho, as exigências da atividade, a dificuldade da função e o desgaste físico e emocional associados à profissão. Ele está intimamente associado à condição proletária, à prisão do trabalho, ao esforço e ao "reino da necessidade" (Marx, 2017).

As gratificações funcionam sob uma lógica distinta. Se o salário é "curto", as gratificações, apesar de representarem uma quantidade semelhante nos rendimentos globais destes trabalhadores, são sempre "elevadas" e de valor "significativo". Se o salário se aproxima, discursivamente, das restrições associadas à classe trabalhadora, mal chegando para cobrir as despesas quotidianas, as gratificações servem para justificar os pequenos luxos e os esporádicos atos de consumo conspícuo. Elas "permitem-me ter uma vida melhor", "pagar a casa em três anos", "fazer uma viagem", "uma tatuagem", "comprar uma mota" e "viver numa zona melhor". José, ex-pagador de banca e ex-dirigente sindical, refere: "eu mobilei a minha casa toda com o dinheiro das gratificações". Na mesma medida, Hugo, pagador de banca com mais de 10 anos de experiência profissional, afirma: "as gratificações permitem-me alguns luxos”. Simultaneamente, a gratificação não é apreendida como uma obrigação. A gratificação é um reconhecimento voluntário dos parceiros. Desta forma, ela é entendida como uma "generosidade" do cliente, uma "bondade do parceiro" ou uma "opção do jogador". Se o salário se associa, facilmente, ao "reino da necessidade", as gratificações estão intimamente relacionadas com o "reino da liberdade" (Ibid.). Ao contrário do salário, que é uma obrigação da empresa, a gratificação é uma opção do cliente. Um está associado à prisão do trabalho, o outro à liberdade do consumo.

Esta dualidade de representações e simbolismos não significa que os trabalhadores, direta e deliberadamente, cubram as despesas quotidianas apenas com o valor dos salários e procurem reservar o valor das gorjetas para os pequenos luxos. Ou seja, as duas formas monetárias não são rigorosamente segregadas, não são utilizadas para "propósitos especiais" (Polanyi, 1957), nem circulam exclusivamente nas suas respetivas "esferas de troca" (Bohannan, 1959; Bloch; Parry, 1989). Estas associações são operadas a posteriori, isto é, os trabalhadores justificam, pos-
21 Como podemos observar por estes testemunhos, os salários possuem, atualmente, bastante importância para estes trabalhadores, ao contrário do que sucedia antigamente. Esta circunstância é explicada pelo declínio progressivo das gratificações, sobretudo, a partir da década de 1990. 
teriormente, os seus gastos com base nesta dicotomia. Se seria impensável e imoral justificar os momentos de consumo conspícuo através do salário, intimamente ligado à condição proletária e à injustiça das relações assimétricas no processo de trabalho e na sociedade, justificar o pagamento das despesas quotidianas através das gratificações seria, igualmente, imoral e extemporâneo, dadas as representações a elas associadas. Para os trabalhadores dos casinos analisados, o dinheiro que explora nunca poderá ser, em simultâneo, o dinheiro que gratifica.

A perpetuação desta representação dualista entre um salário curto e uma gratificação elevada demonstra, não só que o dinheiro tem qualidades para além das quantidades que representa, mas, acima de tudo, que as quantidades são elas próprias qualificadas. Esta dicotomia demonstra como o salário está "embebido" (Polanyi, 2012) numa "economia moral" distinta da gratificação, embora representem duas qualidades do mesmo princípio económico: o dinheiro.

\section{Os sentimentos do dinheiro}

\section{2 de dezembro de 2019, quinta-feira, 19:00.}

Chego primeiro ao tasco onde, há um ano atrás, costumávamos descomprimir depois das aulas práticas do curso de pagador de banca de casino. Ao fim de alguns minutos, aparecem dois antigos colegas meus, que agora trabalham como pagadores de banca num casino do Algarve. Pedimos três cervejas e conversamos sobre os primeiros 6 meses das suas respetivas experiências profissionais. $\mathrm{Ob}$ servo, estupefacto, como os seus discursos sobre as gratificações se aproximam, ao fim de apenas 6 meses de trabalho, dos argumentos dos pagadores de banca que eu já havia entrevistado. Tavares é particularmente enfático: "porque é que os caixas recebem gratificações? Estão ali atrás do balcão, não fazem um caralho". Eu intervenho, mas apercebo-me, imediatamente, da condescendência das minhas palavras: "porque é que vocês se preocupam tanto com as gratificações? Ainda por cima lá em baixo recebem o quê? $300 €$ por mês?”. Paulo intromete-se na discussão: "Sabes porque é que nos preocupamos tanto com as gratificações? Porque são aquilo que nos deixa felizes".

O dinheiro não é um objeto uniforme e homogéneo, nem uma mera abstração do valor (Zelizer, 1989; Hart, 2000; Graeber, 2001; Bloch; Parry, 1989; Gregory, 2005; Maurer, 2006). Ele é um símbolo do valor social (Hart, 2000; Graeber, 2001; Zelizer, 1989). O dinheiro não pode ser apreendido na sua totalidade sem considerações extra-económicas (Zelizer, 1989). Ele não é investido de uma qualidade omnipotente capaz de corromper todos os valores e sentimentos, uniformizando a vida social e cultural (Ibid.). O dinheiro é, ele próprio, corrompido por esses valores e sentimentos, que o investem de significados morais e sociais (Ibid.). Segundo Tiago, pagador de banca com mais de 30 anos de experiência, a gratificação nos casinos "não é uma gorjeta, nem uma contraprestação de trabalho". Como caraterizar as gratificações destes trabalhadores se elas se diferenciam dos salários, por um lado, e das gorjetas concedidas noutros estabelecimentos comerciais, por outro? O mes- 
mo interlocutor providencia, de seguida, uma pista decisiva: "a nossa gratificação é um sentimento. É alguém que está ali e diz: “eu vou comparticipar, toma!”. É um extravasamento do meu contentamento que quero partilhar". Estas fórmulas discursivas não encontram paralelo nos argumentos relativos à retribuição salarial. As gratificações estão do "lado do coração", deixam os profissionais "felizes" e transmitem "sentimentos". Mesmo em contextos laborais onde o salário monopoliza os interesses profissionais, dificilmente encontraremos um trabalhador que justifique a sua preocupação com o salário pela "felicidade" que este lhe traz.

Mas porque se encontram as gratificações associadas a sentimentos como a felicidade? O que motiva estas representações? Nos casinos, a gratificação é uma prática quase institucionalizada. Como a "dádiva", ela é informal e teoricamente voluntária, mas, na prática, é socialmente obrigatória (Mauss, 2011). Nos casinos, a grande generalidade das gratificações não são concedidas com base em avaliações subjetivas sobre a qualidade do serviço prestado, como sucede noutros contextos laborais no setor dos serviços. $O$ jogador gratifica, maioritariamente, quando ganha. No entanto, não basta ganhar. Como refere Tiago:

As gratificações estão dependentes da evolução e da "involução" do jogo. Depende se o jogador ganha ou se o jogador perde. $\mathrm{O}$ bom atendimento não existe, a única coisa é ter uma cara razoavelmente simpática, para não estar a jogar com um gajo de trombas. É esse o nosso atendimento [...], as gratificações surgem mais se houver alguém que vá ganhando e perdendo. Porque cada vez que ganha dá uma ficha. Se perder, perder, perder, não dá nada; se ganhar, ganhar, ganhar, a partir de determinado momento vai-se embora. Agora se ganhar e perder de vez em quando vai dando uma ficha, portanto isto é como uma maré.

Mas a necessidade de derrota do jogador não nos deve iludir. Nesta relação dialética, ela desempenha um papel meramente instrumental: da mesma forma que a maré baixa deve preceder a maré alta, a derrota deve preceder a vitória. A associação entre o jogador que ganha - e que se encontra, por esse motivo, feliz - e a gratificação é óbvia. Assim, a gratificação é a expressão material dos sentimentos do jogador: felicidade, euforia, afeto, etc. A diferença entre as gratificações dos casinos e as gorjetas de outros estabelecimentos comerciais perde agora a sua opacidade. Se a segunda era considerada uma "esmola vexante", a primeira era um "sentimento partilhado".

A gratificação nos casinos é o veículo, ou o médium, que permite concretizar essa partilha de sentimentos. $O$ jogador gratifica porque se encontra grato ao pagador que lhe proporcionou a sorte no jogo. O jogador pretende que o seu estado emocional seja transmitido ao e partilhado pelo trabalhador. Ao gratificar, o jogador garante essa partilha. Da mesma forma, não gratificar é a transmissão de sentimentos de exasperação ou insatisfação com o azar do jogo. Nestes casos, são os próprios trabalhadores que se sentem culpados pelo azar do jogador. Estes sentimentos de culpa costumam ser formulados da seguinte forma: "epa, ontem 
só dei jogo de merda", "tive que pedir para sair da banca, até me sentia mal, só lhes estava a tirar dinheiro, não dava nada a ninguém”. Por essa razão, não ser gratificado quando um jogador ganha é motivo de perplexidade e de ofensa à própria dignidade dos profissionais: "o cabrão ganhou o jackpot de $20000 €$ e não me deu nada”. A indignação é tanto maior, quanto maiores são os prémios obtidos pelos jogadores.

Como podemos observar, as gratificações não apenas têm sentimentos, elas são sentimentos. Elas são, simultaneamente, o dinheiro dos sentimentos e os sentimentos do dinheiro. Ou seja, se por um lado, as gratificações são o representante material do estado emocional que os jogadores pretendem transmitir, por outro, elas próprias são sentimentos, dado que a gratificação, pela sua própria definição baseada na concessão voluntária de dinheiro, é a expressão objetiva e autotélica de um conjunto de sentimentos específicos: felicidade, apego, estima, etc. A utilização do termo gratificação, em detrimento da noção mais comum de gorjeta, não é inocente. A gratificação é gratificante. Isto é, as gratificações não representam apenas os sentimentos do jogador (não são simples objetos passivos), elas são sentimentos a que os jogadores recorrem quando ganham, para expressar o seu respeito e agradecimento pela sorte do jogo ou, simplesmente, para responderem a uma obrigação social incontornável. Nos casinos, parte do prémio alcançado pelos jogadores é sempre gratificação em potencial. A gratificação permanece de forma latente em qualquer prémio ganho e constrange os jogadores à sua concessão. O que significa que a sua concessão não é sempre determinada pelo estado emocional dos jogadores. Por vezes, acontece precisamente o inverso: é ela que determina esse estado emocional que, pela institucionalização e obrigatoriedade da sua prática, coage, independentemente da vontade dos clientes, à sua própria concessão. Se a gratificação, pela sua própria definição, é gratificante, a sua concessão, independentemente da vontade e do estado emocional do cliente, será, na maior parte das circunstâncias, interpretada como a transmissão de sentimentos de felicidade, reconhecimento e partilha de contentamento. Tal não significa que as gratificações sejam sempre apreendidas desta forma. Em raras circunstâncias, quando o jogador que gratifica procura, ativamente, demonstrar o seu descontentamento, as gratificações podem assumir uma forma pejorativa, próxima da definição de "esmola vexante", funcionando como ato de subjugação e hierarquização social. Porém, neste caso, o jogador deve demonstrar através de gestos, atitudes ou comportamentos a sua intenção. Ou seja, para que a gratificação seja apreendida como subjugação, o jogador deve realizar um esforço emocional e performativo para se certificar que ela é percebida dessa forma. No entanto, este é precisamente o ponto, a ação conjunta, dialética e interativa entre pessoas e coisas, constrói a sua "existência mútua" (Zickgraf, 2017, p. 304).

Apesar da quase institucionalização da prática da gratificação, os pagadores de banca não deixam de performatizar várias estratégias com o objetivo de ampliar o valor voluntariamente concedido. Desta forma, os pagadores utilizam as estratégias performativas que Robin Leidner (1993) designava por "alianças de interesses tripartidas", isto é, consoante lhes for mais benéfico no momento, aliam-se à 
casa ou ao jogador. Os profissionais de banca nos casinos em Portugal estão proibidos, legalmente, de solicitar gratificações ${ }^{22}$ (Roque, 2011). No entanto, esta disposição legal é contornada todos os dias de forma indireta. Como já assinalava Greta Paules (1991, p. 34), no seu estudo sobre empregadas de mesa, as gorjetas tendem a produzir uma dinâmica de trabalho de tipo "empreendedor". Desta forma, os trabalhadores tendem a encarar a sua banca como um "palco" (Barnes, 2002), onde, enquanto "actores", apresentam e representam a sua "fachada pessoal" (Goffman, 2002) com o objetivo de angariar mais gorjetas. Neste sentido, o cliente tende a ser apreendido como o "material em bruto a partir da qual a gorjeta é extraída"”23 (Paules, 1991, p. 34). Nesta relação entre trabalhadores, clientes e gorjetas, o sentimental, observado anteriormente, e o instrumental, agora evidente, confundem-se. A "representação sincera" entrecruza-se com a "cínica" (Goffman, 2002, p. 26). Casaca (2012, p. 80) já havia observado que a "humanidade inerente à relação de serviços pode coexistir com uma dimensão mais instrumental". O testemunho de Adriano, pagador de banca com mais de 30 anos de experiência profissional, é elucidativo: "a banca é o meu palco, sou um ator, faço manipulação psicológica. Muitos dos meus colegas deviam ter um curso de psicologia. Não tenho nada a ver com isto lá fora [...]. Eu tiro dinheiro às pessoas e elas ainda saem dali bem dispostas". Esta cultura empreendedora, observada também por Jeffrey J. Sallaz (2009), na sua investigação sobre o trabalho nos casinos em Las Vegas e na África do Sul, adequa-se também ao contexto dos casinos portugueses. Uma primeira estratégia consiste na decomposição do prémio atribuído em unidades (fichas) de determinado valor. $\mathrm{O}$ objetivo é sugerir a gratificação pela própria composição do pagamento. Imaginemos que um jogador ganha um prémio de $100 €$. Este valor nunca deve ser pago com uma única ficha do mesmo valor. Em primeiro lugar, porque o pagador deve realizar o pagamento de acordo com o valor que o jogador tem vindo a apostar. Se o jogador, no último golpe, apostou $5 €$, o pagador deverá efetuar o troco de forma a que essa aposta possa ser reproduzida no golpe seguinte. Em segundo lugar, o jogador nunca vai gratificar o prémio total. Assim, num prémio de $100 €$, o pagador poderá entregar o prémio de acordo com a seguinte composição: uma ficha de $50 €$, uma de $20 €$, cinco de $5 €$ e duas de 2,5€. Desta forma, o pagador amplia a possibilidade de gratificação, sugerindo que, pelo menos as fichas de menor valor, deverão ser devolvidas ao pagador. Mas outras estratégias são performatizadas no âmbito de um trabalho de serviço teatralizado e de interações dramatizadas (Goffman, 2002; Sherman, 2007). No decorrer de um jogo azarado, o pagador de banca tende a exibir um semblante carregado, expressando um sentimento de frustração partilhada. Por vezes, o pagador exclama: "ah, quase... esteve perto", "para a próxima vamos conseguir", "aposte neste número, olhe que se cair aqui, quero a minha parte”. Outros gestos e comportamentos são operacionalizados, quando jogadores mais recalcitrantes se recusam, terminantemente, a gratificar: numa banca pouco proativa na gratificação, os profissionais tendem a lisonjear os "bons exemplos" e a ostracizar os jogadores que não gratificam. Neste exemplo, ao receber a gratificação de um jogador, o pagador afirma: "você está a seguir um bom exemplo, os outros é que não". Ainda
22 Em Las Vegas, esta prática é conhecida por "hustling", ou "forçar", e é também proibida (Barnes, 2002; Sallaz, 2009).

23 "[...] raw material from which the tip is extracted". 
neste caso, o pagador, violando, deliberadamente, a ordem de pagamentos, que se encontra estabelecida por lei, pode decidir pagar, em primeiro lugar, o prémio dos clientes que gratificam. Desta forma, o pagador não apenas determina, para os jogadores que aguardam a sua vez, o exemplo daqueles que gratificam, como estabelece, para os jogadores menos experientes ou recém-chegados à banca, uma aparente obrigatoriedade da prática da gratificação. Uma outra estratégia consiste em reivindicar a responsabilidade pelo resultado do jogo (Sallaz, 2009). O pagador, depois de atribuir os prémios aos jogadores, afirma com um certo orgulho: "vêm? Só não ganha, quem não quer", ou “eu não lhe disse? Não acredita em mim"24. Por fim, os dealers também providenciam conselhos de estratégias aos jogadores que gratificam (Ibid.). Num jogo de blackjack é comum o pagador questionar as decisões do jogador: "tem a certeza?”, “eu não pediria carta”. Quando estes mecanismos não surtem efeito, os pagadores distanciam-se emocionalmente do jogo, entrando em modo "robot” (Hochschild, 2003). Tal como Rachel Sherman (2007, p. 136) sublinha: "os trabalhadores tornam-se crescentemente envolvidos no seu trabalho assim que se tornam investidos no resultado do jogo" ${ }^{25}$. Ou, como reitera Sallaz (2009, p. 51): "quando [...] um jogador oferece uma gorjeta inicial, o comportamento do dealer altera-se dramaticamente, da indiferença para o envolvimento activo"26. Da mesma forma, Maria Polychronis (2008) conclui, reportando-se ao contexto laboral dos empregados de bares, que os trabalhadores dos serviços tendem a investir a sua energia emocional junto de clientes que concedem mais gorjetas. Se as estratégias anteriores permitiam a aliança entre pagador e jogador, o distanciamento emocional assegura a aliança entre trabalhador e empresa, dado que este se refugia nos seus procedimentos de trabalho. A envolvência emocional do pagador no curso do jogo, a sua disponibilidade para mobilizar o seu estado emocional, para partilhar afetos, alegrias e frustrações com os jogadores, depende da prática da gratificação. Caso contrário, os pagadores desligam-se do curso do jogo e deixam que os automatismos comandem os procedimentos formais associados à sua função, distanciando-se emocional e mentalmente dos resultados do jogo e da sorte/azar dos jogadores. Os dealers em Las Vegas costumam designar este fenómeno por “dummy up and deal” (Barnes, 2002; Sallaz, 2009). Como desabafava Marcelo, pagador de banca com cerca de 20 anos de experiência profissional, "que percam, estou-me a cagar, não me dão nada”. A gratificação, não apenas facilita a partilha de sentimentos de felicidade, como permite, ao trabalhador, transitar do "reino da necessidade" para o "reino da liberdade". O pagador gratificado transforma-se num reflexo do jogador, transita do trabalho para o lazer. Tal como o jogador, ele joga. Tal como o jogador, ele tem sorte ou azar. Tal como o jogador, ele torna-se consumidor do produto que ele próprio vende: a experiência do jogo. Como assinala H. Lee Barnes (2002, p. 4), no seu trabalho sobre os dealers em Las Vegas, “eles são atraídos para dentro do jogo” ${ }^{27}$. Ou, como refere Sallaz (2009, p. 11): "nas bancas, os croupiers jogam o seu próprio jogo"28. Se a sorte beneficiou o jogador premiado, a sorte também beneficiou o pagador gratificado, porque a gratificação do pagador depende do êxito do jogador. A este respeito, Tavares, antigo colega do curso de pagador, menciona: "a gente também tem sor-
24 O inverso também acontece. Quando um jogo não corre de feição aos jogadores, o pagador procura desresponsabilizar-se dos resultados, nomeadamente, quando é confrontado por um cliente insatisfeito (Sallaz, 2008).

25 "Workers become increasingly involved in their work as they become invested in the outcome of the game".

26 "When [...] a player does offer an initial tip, the dealer's demeanor changes dramatically, from indifference to active engagement".

27 "[...] he or she is drawn into the play". 28 "On the tables, croupiers play their own game". 
te”. O resultado final destas diversas performances estéticas e emocionais é uma experiência de agência, que evidencia a sua capacidade de controlar a acção e as interacções numa banca de jogo (Ibid.). Ao mesmo tempo, ao conceberem os clientes como material em bruto a partir do qual extraem as suas gorjetas (Paules, 1991), os pagadores apreendem-se como superiores, autoritários, qualificados, controladores, invertendo, simbolicamente, as herarquias sociais que os subordinam e constituindo-se como agentes não subordinados (Sherman, 2007; Lamont, 2000). Ao controlarem a distribuição, selectiva, das suas ofertas emocionais, ao privilegiarem os jogadores que gratificam, em detrimento dos que não gratificam, ao trocarem "capital económico" por "capital emocional”, os pagadores manipulam o seu contexto de subordinação (Ibid.; Sallaz, 2009).

A negação das hierarquias sociais e, em particular, do seu estatuto subordinado nas interações com os clientes explica, igualmente, a preferência pelo termo "parceiro", em detrimento da noção mais comum de cliente. O primeiro, ao contrário do segundo, transmite uma imagem igualitária da relação entre trabalhador e jogador. Ao mesmo tempo, a utilização deste termo está intimamente associada aos sentimentos envolvidos na concessão da gratificação. Como assinala Mateus, pagador de banca já reformado, "nós não jogamos contra o parceiro e ele não joga contra nós". O jogador aposta contra a casa e o pagador, embora em representação do casino, deseja o sucesso do jogador, dado que tal significa, muito provavelmente, a ampliação do valor das suas gratificações. Da mesma forma, Hugo refere que a noção de parceiro "dá uma sensação que não é de antagonismo. Está ali connosco... a partilhar alguma coisa connosco". Mas, mais significativamente, a noção de parceiro está dependente da prática da gratificação. $O$ parceiro não é um termo aplicável a todos os jogadores, é, pelo contrário, uma categoria muito específica de clientes. Ricardo, pagador de banca com cerca de 15 anos de experiência profissional, assinala que o parceiro é um jogador frequente, que "joga forte" e que gratifica com regularidade. $O$ desempenho de "diferentes papéis para diferentes auditórios", ou, resumidamente, a "segregação do auditório" (Goffman, 2002, p. 52), consiste na hierarquização dos jogadores com base no volume e na regularidade da gratificação. Este fenómeno não é uma inovação dos pagadores de banca em Portugal. Em Las Vegas, os clientes que gratificam abundantemente são designados por "Georges", "G" de "generosos"29 (Sallaz, 2009; Barnes, 2002). Da mesma forma, em Portugal, o jogador é considerado um parceiro apenas na medida em que gratifica e em que partilha os seus sentimentos de felicidade com os trabalhadores. Em que, por essa via, consegue envolver sentimentalmente os pagadores no jogo. Se o jogador se emociona ao ganhar, o pagador emociona-se ao ser gratificado. Trabalhador e parceiro fazem parte, como refere Mateus, "do mesmo meio". Este "meio" é o casino e o universo da contingência, isto é, o universo da sorte e do azar.

O pagador tem interesse em reproduzir este imaginário de equivalência e de ligação emocional ao jogador, dado que tal lhe permite ampliar o valor das suas gratificações. Mas os jogadores também procuram perpetuar essa ligação emocional. Sejam quais forem as reais motivações dos jogadores, os pagadores de
29 Da mesma forma, os jogadores que não gratificam são conhecidos por "stiffs", isto é, "inflexíveis" (Barnes, 2002; Sallaz, 2009). 
banca formulam as suas próprias hipóteses. Segundo as suas perspectivas, em primeiro lugar, os jogadores cedem parte dos seus prémios como forma de agradecimento, dado que os pagadores influenciam, decisivamente, os resultados do jogo. O que não significa que os trabalhadores tenham a capacidade de controlar ou prever os resultados do jogo, mas que, com outros pagadores, esses resultados, provavelmente, teriam sido diferentes. Esta situação é mais evidente na roleta. Cada pagador empurra o prato da roleta com determinada força, lança a bola a determinada velocidade e efetua todos estes procedimentos com movimentos e técnicas específicas. Mesmo não controlando os resultados do jogo, foi pela mão de determinado pagador que o prémio foi obtido. Em segundo lugar, a gratificação assegura o envolvimento emocional do pagador no jogo. Ao gratificar, o jogador coloca o pagador do seu lado, coopta-o para a sua equipa, garantindo o seu suporte moral contra o adversário comum: a casa. Em terceiro lugar e como já referido, a gratificação funciona segundo uma lógica semelhante à da "dádiva” (Mauss, 2011). A gratificação cria uma dívida, uma obrigação de reciprocidade. Ao gratificar, o jogador está a premiar um pagador que lhe deu sorte e, ao mesmo tempo, a creditar nesse trabalhador a obrigação de retribuir o gesto com mais sorte futura. $\mathrm{O}$ testemunho de Helena confirma esta análise:

A gratificação é uma generosidade do cliente, ele não é obrigado a dar, mas se ele não der metemos logo um grande X em cima daquela pessoa. "Vai-te correr mal o jogo" e quando perde nós até fazemos um ar de "está a ver?". Os jogadores mais antigos gratificam porque te obriga, se não derem é mau, podem perder. Nós queremos que eles pensem todos assim: "se eu não der, isto vai correr muito mal".

Desta forma, apesar de representar a casa, o pagador alia-se, através da dádiva da gratificação, ao jogador. Ele assume, assim, uma posição contraditória e instrumental no processo laboral:

Os dealers agem de acordo com os seus próprios interesses, não se identificando sistematicamente com a casa nem com os jogadores [...], por vezes aliam-se ao casino, procurando esgotar os fundos de um jogador que não gratifica; noutras circunstâncias, aliam-se aos jogadores que gratificam, desejando que eles ganhem ${ }^{30}$ (Sallaz, 2009, p. 61).

Estas observações não passam despercebidas aos próprios pagadores de banca dos casinos analisados. Maria, pagadora de banca com mais de 10 anos de experiência profissional, assinala: "nós estamos numa posição muito ingrata, porque nós, enquanto trabalhadores da empresa, queremos que eles [os jogadores] percam, mas enquanto pessoas que ganham gratificações, queremos que eles ganhem. [...] Temos sempre que jogar com isto"31 . Por fim, a prática da gratificação permite apurar o resultado de um outro tipo de competição. Erving Goffman (2011), tendo, ele próprio, exercido a profissão de croupier em Las Vegas, assinalara que, numa banca, não é apenas o valor da aposta que está em jogo, mas o próprio “caráter" (Ibid.). Ou, como diria Clifford Geertz (1973) em relação à luta de galos balinesa, o
30 "Dealers act in their own interest, systemically identifying with neither the house nor the players [...], at times they may side with the casino to drain the bankroll of a non-tipping player; at others, they may side with a tipping player wishing to win big".

31 Maria e Helena são as duas únicas pagadoras de banca citadas neste artigo. Esta diminuta representatividade feminina explica-se pela persistente constituição e reconstituição de uma força de trabalho eminentemente masculina nos casinos em Portugal. Por questões de espaço, este tema não será abordado neste artigo. A análise sobre o género nos casinos será aprofundada num artigo próprio (Gomes, no prelo). 
jogo é um "drama de status", onde se joga a "honra" dos participantes. O resultado do jogo é, portanto, uma "competição de caráter; um tipo especial de jogo moral" (Goffman, 2011, p. 228). O valor das apostas não é uma mera referência pecuniária, mas uma indicação de status e de caráter, a sobriedade perante a derrota, o desinteresse pelo dinheiro perdido, o dobrar da aposta e a prática da gratificação são demonstrações de "caráter forte", isto é, de "coragem, combatividade, integridade, compostura" (Ibid., p. 218). Gratificar, principalmente quando se perde, é sinal de estatuto e de reconhecimento. Numa noite de trabalho, no decorrer da minha pesquisa de terreno, um pagador de banca na roleta estava visivelmente frustrado dada a ausência de gratificação. A determinada altura, comentou com o fiscal de banca ao seu lado: "ninguém dá nada à gente, oh Zé". Um jogador fitou o pagador com algum desconforto, outro desviou o olhar, mas um terceiro respondeu orgulhosamente: "oh amigo, vê lá que eu até gratifico quando perco, ainda há pouco ali no blackjack'. O pagador desculpou-se, mas o jogador interrompeu-o: "fale para os outros, eu gratifico". Gratificar, como apostar forte, é sinal de estatuto, de afluência e de caráter.

Assim, o processo de angariação de gorjetas nos casinos "é um jogo dentro de um jogo" 32 (Barnes, 2002, p. 44). É um jogo no sentido empregado por Burawoy (1979), Sherman (2007) e Sallaz (2009). Ao transformar a atividade laboral, a monotonia e o esforço que nela estão implicados, num jogo, os trabalhadores transformam, temporariamente, o trabalho em lazer, concebem-se como agentes não subordinados e autónomos e criam a dignidade na subordinação (Sherman, 2007). Autónomos em relação à empresa, pela sua menor dependência em relação ao salário, e autónomos em relação aos clientes, vistos não como agentes opressores, mas como parceiros que partilham os seus sentimentos, ou como material em bruto a partir do qual extraem as suas gorjetas. Esta aparente libertação favorece a construção de si mesmos como agentes não subordinados (Ibid.). Mas, ao mesmo tempo, o jogo produz consentimento: em primeiro lugar, porque os conflitos laterais acabam por substituir as potenciais tensões hierárquicas; e, em segundo lugar, porque ao criarem a dignidade na subordinação, estes trabalhadores normalizam a sua condição de subordinação estrutural (Burawoy, 1979; Sherman, 2007). Os trabalhadores dos casinos, convertidos em empreendedores (Sherman, 2007; Paules, 1991; Sallaz, 2009), isto é, em agentes responsáveis pelos seus próprios rendimentos, fragmentam-se internamente em categorias profissionais, numa luta pela apropriação das gratificações, em detrimento de uma luta potencialmente unitária pelos salários. A empresa, por sua vez, aproveita a existência das gratificações para reduzir, substancialmente, a retribuição salarial dos pagadores de banca. Como tal e apesar da conceção de autonomia profissional que as gratificações emprestam a estes trabalhadores, elas favorecem, sistematicamente, a perpetuação das relações assimétricas entre capital e trabalho. Na verdade, elas não se dissociam destas relações de dominação e exploração. A apreensão das gorjetas no âmbito de uma "economia moral" diferenciada favorece a conceção de que estas se encontram afastadas das relações de poder tipicamente capitalistas. Porém, embora funcionando segundo princípios distintos da retribuição salarial, 
as gorjetas são um "mecanismo informal compensatório", ou seja, um complemento necessário dessas mesmas relações.

\section{Conclusão}

Como podemos observar, os "habitus" profissionais, os "universos simbólicos" e os "mapas cognitivos" dos pagadores de banca dos dois casinos analisados encontram-se significativamente condicionados pela existência das gratificações. Simbolicamente, pelas representações que transportam, e materialmente, pelas práticas que estão implicadas na sua concessão e angariação. As gratificações são reguladas por uma "economia moral" distinta da que está implicada na retribuição salarial. Em primeiro lugar, as gratificações conduziram, historicamente, ao corporativismo sindical, às práticas de closed shop e ao clientelismo que ainda hoje sobrevive nas políticas de recrutamento destes dois casinos. Estas práticas de "oclusão social”, mobilizadas por estes trabalhadores, visavam, sobretudo, preservar o valor das suas gratificações e impedir a vulgarização do seu título profissional. Atualmente, apesar da equivalência quantitativa dos salários e das gratificações, estas duas componentes remuneratórias continuam a ser representadas de formas distintas. Se o salário é "curto" e “injusto”, as gratificações são "elevadas”. Se o primeiro se associa às relações de poder na empresa e na sociedade, ao universo do trabalho e ao "reino da necessidade", a segunda emancipa os trabalhadores para o universo do consumo e para o "reino da liberdade". Se o salário corresponde a uma obrigação e é um instrumento opressor, as gratificações são uma "generosidade", uma "partilha de sentimentos" e um veículo para a "felicidade". Ao mesmo tempo, as gratificações produzem uma dinâmica laboral e relacional distinta, que permite veicular sentimentos de autonomia profissional, ao mesmo tempo que, estruturalmente, favorece a reprodução das relações assimétricas entre capital e trabalho. As gratificações e os salários são representados e agenciados de acordo com moralidades distintas, mas não deixam, apesar de tudo, de se articularem no interior de um sistema económico eminentemente assimétrico, assente na dominação e exploração laboral. 


\section{Referências}

ACORDO Colectivo de Trabalho entre a Empresa Estoril-Plage e o Sindicato Nacional dos Empregados de Banca nos Casinos. Boletim do Instituto Nacional do Trabalho e Previdência, ano XII, 1945.

ACORDO Colectivo de Trabalho entre a Empresa Sointal e o Sindicato dos Empregados das Salas de Jogos dos Casinos. Boletim do Trabalho e Emprego, $1^{\text {a }}$ série, n. 21, v. 44, 1977.

ACORDO Colectivo de Trabalho entre a Empresa Sociedade Figueira-Praia e o Sindicato dos Empregados das Salas de Jogos dos Casinos. Boletim do Trabalho e Emprego, $1^{\text {a }}$ série, n. 9, v. 46, 1979.

ACORDO Colectivo de Trabalho entre várias empresas concessionárias de jogo e o Sindicato Nacional dos Empregados de Banca nos Casinos. Ofício 54. 1952-1967. Arquivo Nacional da Torre do Tombo. Código de referência: PT/TT/SAS/003/002/00088. Cota actual: Serviços de Acção Social, cx. 8, proc. 24.

APPADURAI, Arjun. The social life of things: commodities in cultural perspective. Cambridge: Cambridge University Press, 2000.

ASSOCIAÇÃO de Classe dos Empregados dos Clubs e Casas de Recreio de Lisboa, 1929. Relatório de Direcção e Parecer da Comissão Revisora de Contas. Arquivo Histórico na Área Económico-Social (ARQUESOC). Ministério do Trabalho, da Solidariedade e da Segurança Social. Gabinete de Estratégia e Planeamento. Disponível em: http:// arquesoc.gep.msess.gov.pt/projecto1/index.htm. Acesso em: 19 out. 2018.

BARNES, H. Lee. Dummy up and deal: inside the culture of casino dealing. Reno: University of Nevada Press, 2002.

BLOCH, Maurice; PARRY, Jonathan (eds.). Money and the morality of exchange. Cambridge: Cambridge University Press, 1989.

BOHANNAN, Paul. The impact of money on an African subsistence economy. The Journal of Economic History, v. 19, n. 4, p. 491-503, 1959.

BOURDIEU, Pierre. A distinção: uma crítica social da faculdade de juízo. Lisboa: Edições 70, 2010 [1979].

BURAWOY, Michael. Manufacturing consent: Changes in the labor process under monopoly capitalism. Chicago: University of Chicago Press. 1979.

CASACA, Sara Falcão. Trabalho Emocional e Trabalho Estético na Economia dos Serviços. Coimbra: Almedina. 2012.

DECRETO-LEI n 5516 de 7 de Maio de 1919 do Ministério do Trabalho. Direcção Geral do Trabalho - Repartição de Defesa do Trabalho. Diário do Governo, n. 95/1919, série I.

DECRETO-LEI n 14643 de 3 de Dezembro de 1927 do Ministério do Interior. Diário do Governo, n. 267/1927, série I.

DECRETO-LEI n 21861 de 15 de Novembro de 1932 do Ministério do Interior. Diário do Governo, n. 268/1932, série I.

DECRETO-LEI n 24402 de 24 de Agosto de 1934 da Presidência do Conselho. Sub-Secretariado de Estado das Corporações e Previdência Social. Diário do Govêrno, n. 199/1934, série I.

DECRETO-LEI n 43044 de 2 de Julho de 1960 do Ministério do Interior. Conselho de Inspecção de Jogos. Diário do Governo, n. 152/1960, série I. 
DESPACHO normativo do Ministério das Corporações e Previdência. Distribuição das gratificações do pessoal que presta serviço nas salas de jogo de fortuna ou azar. 1960. Boletim do Instituto Nacional do Trabalho e Previdência, ano XXVII.

GEERTZ, Clifford. The interpretation of cultures. Nova lorque: Basic Books, 1973.

GOFFMAN, Erving. A representação do eu na vida cotidiana. São Paulo: Vozes, 2002 [1956].

GOFFMAN, Erving. Ritual de interação: ensaios sobre o comportamento face a face. São Paulo: Vozes, 2011 [1967].

GOMES, João. Como construir privilégio: a distribuição assimétrica das gratificações nos casinos em Portugal. Antropológicas, 15, p. 8-30, 2019.

GOMES, João. no prelo. A produção de identidades de género e de classe em dois casinos portugueses: o caso das barmaids e das pagadoras de banca. Análise Social.

GRAEBER, David. Toward an anthropological theory of value: the false coin of our own dreams. Nova lorque: Palgrave Macmillan, 2001.

GRATIFICAÇÕES das salas de jogos dos casinos - projectos A e B. 1981-1983. Arquivo do Ministério do Trabalho, da Solidariedade e Segurança Social. Código de referência: TR/2, n. 3134.

GREGORY, Chris. Savage money: the anthropology and politics of commodity exchange. Amesterdão: Harwood Academic Publishers, 2005.

HART, Keith. The memory bank: money in an unequal world. Londres: Profile, 2000.

HOCHSCHILD, Arlie Russell. The managed hearth: commercialization of human feeling. California: University of California Press, 2003 [1979].

LAMONT, Michèle. The dignity of working men. New York: Russell Sage, 2000.

LEIDNER, Robin. Fast food, fast talk. Berkeley: University of California Press, 1993.

MARX, Karl. O Capital. v. I, tomo I. Lisboa: Edições Avante!, 1990 [1867].

MARX, Karl. Manuscritos económico-filosóficos. Lisboa: Edições 70, 2017 [1844].

MAURER, Bill. The anthropology of money. Annual Review of Anthropology, n. 35, p. 5-36, 2006.

MAUSS, Marcel. Ensaio Sobre a Dádiva. Lisboa: Edições 70, 2011 [1925].

MÓNICA, Maria Filomena. Artesãos e operários: indústria, capitalismo e classe operária em Portugal - 1870-1934. Lisboa: Edições de Ciências Sociais, Universidade de Lisboa, 1986.

NUNES, Américo. Diálogo com a história sindical: hotelaria de criados domésticos a trabalhadores assalariados. Lisboa: Editorial Avante!, 2007.

PARKIN, Frank. The Marxist theory of class: a bourgeois critique. Londres: Tavistock, 1979.

PATRIARCA, Fátima. A regulamentação de trabalho nos primeiros anos do regime corporativo. Análise Social, v. 128, n. 4, p. 801-839, 1994.

PAULES, Greta. Dishing it out: power and resistance among waitresses in a New Jersey restaurant. Philadelphia: Temple University Press, 1991.

POLANYI, Karl. The economy as instituted process. In: POLANYI, Karl; ARENSBERG, Conrad Maynadier; PEARSON, Harry (Eds.). Trade and Market in the Early Empires: economies in history and theory. Nova lorque: The Free Press, 1957. p. 243-270.

POLANYI, Karl. A Grande Transformação: as origens políticas e económicas do nosso 
João Gomes

tempo. Lisboa: Edições 70, 2012 [1944].

POLYCHRONIS, Maria. Seduction and power: dynamics between servers and customers in bars. Montreal: Concordia University, 2008.

ROQUE, Vasco. A lei do jogo e seus regulamentos: anotada e comentada. Coimbra: Coimbra Editora, 2011.

SALLAZ, Jeffrey. Deep Plays: a comparative ethnography of gambling contests in two post-colonies. Ethnography, v. 9, n. 1, p. 5-33, 2008.

SALLAZ, Jeffrey. The labor of luck: Casino capitalism in the United States and South Africa. Berkeley: University of Califórnia Press, 2009.

SANTOS, Boaventura de Sousa. Estado e sociedade na semiperiferia do sistema mundial: o caso português. Análise Social, 87, 88, 89 (3, 4, 5), p. 869-901, 1985.

SHERMAN, Rachel. Class Acts: service and inequality in luxury hotels. Berkeley; Los Angeles; Londres: University of California Press, 2007.

THOMPSON, Edward Palmer. A economia moral da multidão na Inglaterra do século XVIII. Lisboa: Antígona, 2008 [1979].

VAQUINHAS, Irene Maria. Nome de código 33856: os jogos da fortuna ou azar em Portugal entre a repressão e a tolerância (de finais do século XIX a 1927). Lisboa: Livros Horizonte, 2006.

WEBER, Max. Economy and society. Berkeley: University of California, 1968 [1922].

ZELIZER, Viviana. The social meaning of money: special monies. American Journal of Sociology, v. 95, n. 2, p. 342-377, 1989.

ZICKGRAF, Jens. Becoming like money: proximity and the social aesthetics of moneyness. HAU: Journal of Ethnographic Theory, v. 7, n. 1, p. 303-326, 2017. 